\title{
Jejak Daun di Situs Wonoboyo
}

\author{
nfn. Siswanto
}

Keywords: leaf, impression, ecofact, Hindu-Buddha

\section{How to Cite:}

Siswanto, nfn. Jejak Daun di Situs Wonoboyo. Berkala Arkeologi, 13(3), 73-84. https:// doi.org/10.30883/jba.v13i3.618. https://doi.org/10.30883/jba.v13i3.618

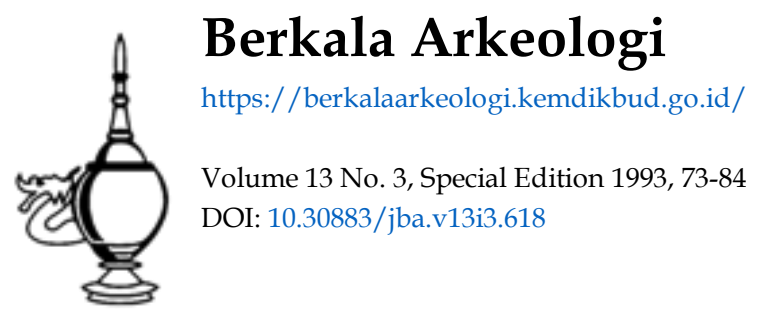

\section{(c) (i) (3)}

This work is licensed under a Creative Commons Attribution-NonCommercial-ShareAlike 4.0 International License. 


\title{
JEJAK DAUN DI SITUS WONOBOYO
}

\author{
Oleh: \\ Siswanto
}

\section{I.Pendahuluan}

Situs Wonoboyo muncul dikenal masyarakat oleh karena telah ditemukannya artefak emas oleh penduduk setempat, pada bulan Okiober dan Desember 1990. Nilal ekonomis dan nilai historis remuan artefak emas tersebut yang sangat besar mendapat perhatian masyarakat, tidak luput perhatlàn kalangan masyarakat IImiah datam hal ini arkeolog dan disiplin terkait lalnnya, untuk mengungkap misteri masa lampau di kawasan tersebut.

Penelitian-penelitian telah dilakukan oleh berbagal pihak yang terkalt sejak Oktober 1990. Dafi hasil serangkalan peneilianpenetitian tersebut teridentifikasi adanya beberapa bagian situs pemukiman (sertlement), yaltu berdasarkan temuan berupa afiefak keseharian sepertl keramik dan gerabah (Anonim, 199y). Namun untuk membuktikan arah status situs yang lebih jolas diperlukan data dan penelitian khusus.

Berdasarkan pengamatan temuan dan lapisan tanahnya, terdapat gejala adanya labih darl satu laplsan budaya, sedang pada baglan lain hanya satu lapis budaya (Anonim, 1991).

Pada bulan Desember 1991 Balal Arkeologi Yogyakarta melakukan penelitian pada situs tersebut, salah satu hasil dan porlu perhatian adalah temuan lapisan tanah (lapls tuff) mengandung sisasisa tumbuhan yaltu jejak daun (leaf impression) pada beberapa kotak uj. Schingga diharapkan data inl dapat memicantu interpretasi status situs Wonoboyo lebih Jelas. Penemuan semacam Inl Jarang ditemukan pada situs-situs arkeologl lain, terutama temuan sisa-sisa tumbuhan.

Jejak daun dalam penelitian arkeologi merupakan data yang dapat dinilal sama penting dengan temuan arkeologis lainnya. Tamuan data berupa jejak daun Inl torutama untuk membantu tolaah mengenal vegetasl masa lalu yang berkaltan dengan situs tersebut. Dimbleby (1978) menegaskan bahwa cotakan tisik dari material tumbuhtumbuhan amat spesifik untuk cataten vegotasl, sekalipun material itu 
sendiri sebenarnya sudah hilang. Endapan/deposit serupa dapat menunjukkan keadaan hidrologi pada masa lampau.

Selama inl studi vegetasi lingkungan masà lalu sering digunakan adalah analisis mikroskopis terhadap pollen dan spora, karena slfat fisis dan khemis yang dimillki oleh baglan tumbuhan inl sangat memungkinkan tersimpan lama di dalam tanah sehlngga mudah ditemukan dimana-mana. Namun pollen dan spora $\mid \mathrm{nl}$ mudah tertransportasi (terbawa) angin maupun air seningga untuk studi vegetasi lingkungan pada kawasan situs secara mikro maupun meso kurang menguntungkan.

\section{Lokasi}

Situs Wonoboyo secara administratif termasuk dalam wilayah Dusun Plosokuning. Desa Wonoboyo, Kecamatan Jogonalan. Kabupaten Klaten Jawa Tengah. Sedangkan secara kultural terletak $4,5 \mathrm{~km}$ sebelah tImur kompleks Candi Prambanan.

Seluruh situs tertutup oleh endapan material vulkanis gunungapi Merapl, terdiri darl endapan lahar dan material piroklastik lainnya. Situs inl merupakan rangkalan berituk lahan bentukan asal gunungapi dengan proses fluviainya, sehingga termasuk dalam lereng kaki fluvial gunungapi / Fluvio-volcanic-footslope (Anonim, 1992).

Dalam penelitian yang dilakukan oleh Balai Arkeologi tanun 1991 membuka 5 korak uji yaitu kotak i'13, kotak $x^{\circ} 6$, kotak j"11, kotak $9^{m} 29$ dan kotak 0m57. Keseluruhan diperoleh temuan jejak daun, namun kotak paling padat ditemukan akumulasi daun adalah pada kotak dengan kode 0 mo5.

Temuan rata-rata dlperoleh pada kedalaman kurang leblh 200 meter yaitu pada lapisan tuff yaitu pengendapan butlran partlkel tanah dalam suspensi air hasil pencuclan permukaan (surface wash) maupun endapan debu vulkanik setebal kurang leb/h $10 \mathrm{~cm}$, lapisan atas dan bawahnya blasanya lapisan lahar yang lebih tebal berpasir kasar.

Temuan-temuan tersebut hanya berbentuk jejak daun dan tidak (belum ?) diperoleh temuan bagian lain misalnya ranting. bill, buah maupun bagla lainnya. Terutama pada kotak $0^{m 57}$. Menurut Drs. Sunarto SU. ( Staf Pengajar Fakultas Geografi UGM./anggota Tim Penelltian Wonoboyo) menegaskan bahwa; lapisan dimana ditemukan 
Jejak daun sangat tlpls (kurang lob/h $10 \mathrm{~cm}$ ), sepanjang lapisan darl atas sampal kedalaman tanah mengandung air dan berpasir best hanya lapisan atas/permukaan saja (top soll atau lapls olah sekarang) yang menjadi tanah. Tidak adanya laplsan tanah pada kotak ini dapat dibuktlkan tidak adanya akar-akar tumbuhan, sehingga dugaan sementara pada daerah Inl (kotak 0"57 sekitarnya) dahulunya merupakan daerah cekungan, kolam, empang, rawa belakang back swamp) yang tergenang air berslfat sementara.

Proses terjadinya Jejak daun-daunan dapat terjadl dimulal dari daun-daun di permukaan tanah yang terbawa aliran air hujan $k e$ daerah yang lebih rendah, pada tempat yang rendah tersebut air tergenang/tidak mengalir. Kemudian daun-daun tersebut mengendap ke dasar cekungan bersamaan dengan pengendapan partikel-partikel tanah, sehingga dapat terbentuk jejak daun saling over laping satu sama lain.

\section{Pengamatan dan Hasll}

Pengamatan dengan identifikasi terhadap jejak daun dilakukan dengan pendekatan melaui kajlan ciri-ciri morfologis jejak daun yang bersangkutan. Pengamatan ditekankan hanya pada daun karena tidakbelum ditemukan bagian lain dari tumbuhan selain daun, sehingga sedapat mungkin berdasarkan temuan daun dapat mengidentiflkasi hingga menyebut spesies tumbuhannya.

Kajian morfologis daun dilakukan dengan memperhatikansifatsifat yang dimillki daun yaltu:

a. Bangun daun (sircum folli)

b. Tepl daun (margo folin)

c. Ujung daun ( apex folii)

d. Pangkal daun (bas/s folli)

e. Susunan tulang daun (nervatto atau venatio) dan

f. Hal-hal lain mengenal permukaan atas maupun bawah daun.

Untuk membantu deskrlpsl dan Identlflkasl masing-masing temuan berdasarkan catatan cirl-clri morfologls tersebut, kemudian dllakukan pengamatan kepustakaan dengan merujuk pada Flora yang ditulis Dr. C.G.G.J. van Steenis (1988), Flore of Java (Spermatophytes Only) oleh C.A. Backer, D.Sc. dan R.C. 
Bakhulzen Van Den Brink Jt. Ph.D (1968) dan Taxonomy of Vascular Plants oleh George H.M. Lawrence. (1968).

Hasll pengamatan diperoleh beberapa spesles tumbuhan yaltu sebagal berlkut:

Nama Latin

1. Artocarpus communis Forst Keluwlh

2. Artocarpus heterophylla Lamk. Nangka

3. Bambusa sp.

4. Cytrus maxima Merr.

5. Durio zibethinus L.

6. Erythrina varlegata L.

7. Hibiscus tiliaceus $\mathrm{L}$.

8. Manglfera indica $\mathrm{L}$.

9. Tectona grandis L.f.
Nama Indonesia

Bambu

Jeruk

Durlan

Dadap

Waru

Mangga

Jati

Deskipsi:

1. Artocarpus communis Forst. (keluwih)

Daun-daun pohon berbunga bertoreh/tepl daun bercangap menyirip (pinnatiflssus), blla tepl daun bercangap dan lekukannya menglkuti susunan tulang daun yang menyirlp, berbentuk lonjong dengan lebar cuncate atau obtuse dasar, 3-7 cuping disepanjang teplan, cuping erecto-patent, membujur, agak memanjang meruncing tajam, bulu-bulu pada urat daun pada kedua permukaan atau pada glaborus bawah, ukuran 30-100 cm $\times 25-65 \mathrm{~cm}$, sampal $1100 \mathrm{~m}$ dpl.

2. Artocarpus heterophylla Lamk.(nangka)

Daun penumpu segitlga bulat telur, daun biasanya tidak berlekuk, hanya daun pada pohon muda dan tunas alr dengan lekuk besar 3$5 \mathrm{~cm}$, tangkal $1-4 \mathrm{~cm}$, helalan memanjang atau bulat telur terballk, ukuran 10-25 $\times 4,5 \quad-10 \mathrm{~cm}$ dengan pangkal menyemplt demi sediklt, tepl daun rata, serupa kullt, darl atas mengkllat hujau tua, 50-1200 $\mathrm{m}$ dpl. 


\section{Bambusa sp. (bambu)}

Bangun daun garis (lienearis) atau tidak ada baglan daun yang terlebar, susunan tulang daun sejajar (rectinervis), ujung daur meruncing dan pangkal daun mebulat (obtusus).

\section{Cytrus maxima (jeruk)}

Tangkal daun panjang $1-8 \mathrm{~cm}$, bersayap sepertl daun, helalan daun bulat telur, memanjang, ellptis, dengan ujung meruncing dan kerap kali melekuk kedalam, tepi rata sampai melekuk kedalam berlinggit, panjang $5-20 \mathrm{~cm}, 11000 \mathrm{~m} \mathrm{dpl}$.

5. Durio zibethinus L.(durian)

Daun bertangkai, memanjang, dengan pangkal membulat dan ujung meruncing, 6-25 kali $2,5-9 \mathrm{~cm}$, sepertl kulit, tulang daun menyirip, 1-800 m dpl.

6. Erythrina variegata L. (dadap)

Poros daun dengan tangkal panjang $10-40 \mathrm{~cm}$, tidak berduri tempel, anak daun bulat telur terballk, segitlga atau bentuk belah ketupat dengan ujung tumpul, tepi rata, Jarang berlekuk sedlklt, sampai $1200 \mathrm{~m}$ dpl.

7. Hibiscus tillaceus L. (waru)

Daun bertangkal, berbentuk Jantung, lingkaran lebar atau bulat telur, tldak belekuk, garis tengah sampal $19 \mathrm{~cm}$, tulang daun menjarl, sebagian tulang daun utama dengan kelenjar berbentuk celah pada sisi bawah pada pangkal.

8. Manglfera indica L. (mangga)

Daun bertangkal, bentuk lanset memanjang, dengan ujung meruncing. seperti kullt, ukuran 10-32 kall 2-10 cm, pada kedua belah sisl tulang daun tengah dengan 12 - 25 tulang daun samping. tepl daun rata (Integer), 1-500 m dpl.

9. Tectona grand/s L.f. (jatl)

Daun bertangkal pendek, kadang-kaoang duduk, ellips atau seaikn banyak bulat telur, dengan ujung yang berbentuk bajl dan baglan 
pangkal yang menyemplt, ukuran $23-40$ kall $11-21 \mathrm{~cm}$, sampal $650 \mathrm{dpl}$.

Secara kualltatip variasl bentuk daun yang telah dlamatl sangat banyak dan sebagian tidak dapat diperoleh bentuk utuh atau tidak dapat dlgambarkan secara utuh, sehingga belum banyak jenls yang dihasilkan.

\section{Pembahasan dan Kesimpulan}

Telaah mengenal vegetasi dalam perlode tertentu pada masa lalu adalah upaya membantu rekonstruksl sejarah kehidupan dan budaya pada jamannya. Informasl lingkungan vegetasi dapat menggambarkan bagaimana dan apa perlakuan manusia terhadap alam lingkungannya, termasuk tumbuhan sekitarnya. Apakah sebagal sumber pangan, pelindung/peneduh, bahan bangunan, penunjang kegiatan sehari-hari atau sebagal perabot/peralatan rumah tangga dan sebagalnya. Berdasarkan informasi spesies tumbuhan yang ditemukan pada suatu tempat dapat memberikan gambaran tentang habitat setempat.

Sebagai gambaran tentang lingkungan vegetasi situs Wonoboyo pada masa lampau dapat kita bandingkan dengan vegetasl yang ada sekarang. Prinsip unlformitarism menyebutkan bahwa the present ${ }^{-1}$ the key of the past. Diduga bahwa makhluk hidup masa lampau mempunyal keadaan sepertl makhluk hidup yang ada di masa sekarang (Matthew; 1962:2).

Data mengenal flora pada masa klasik dl Indonesla dapat dijumpal pada prasastl maupun pada relief-rellef candl, faktor llngkungan dapat mempengaruhl terhadap pemahat, perancang atau seniman dalam menuangkan ide untuk model relief, yaltu apa yang mereka lihat, kenal dan alami dalam lingkungan kehldupan seharl-harl.

Candl Borobudur yang diperklrakan dibangun pada abad VIII $M$. terdapat rellef yang manggambarkan adanya flora maupun fauna. Rellef Karmawibhangga pada candl Borobudur menggambarkan adanya sumber pangan berupa buah-buahan berpatl dljumpal pada serl 0 nomor 50 yaltu nangka (Artocarpus heterophylla), seri 0 nomor 93 yaltu sukun (Artocarpus communis) dan serl 0 nomor 61 yang menggambarkan plsang (Musa peradlslaca) (Sarwono, 1985: 38,44 \& 95 vlde Sukardi, 1986). 
Data lain dalam relief Karmawtbhangga antara lain: seri 0 nomor 65 yaltu padl (Orlza sattva), seri 0 nomor 122 yaitu jewawu: (Setarla italica)seri 0 nomor 34 yaltu plnang (Areca catechu L.). serl 0 nomor 97 yaltu kelapa (Cocos nucifera)(Sarwono, 1985: 152, 80 vide Sukardi, 1986).

Buah-buahan lain yang tidak dljumpal datanya pada prasasti namun penggambaranya ditemukan pada relief Karmawibhangga antara lain adalah Jeruk (Cytrus sp.), mangga (Mariglfera indica), pisang (Musa paradislaca), dan durian (Durio zibethinus)(Sukardi, 1986).

Mengenal bambu (Bambusa sp.h. Steenis (1988) mengemukakan bahwa bambu tidak dapat dlpisahkan darl pedesaan, bambu adalah sebagal bahan bangunan dan untuk segala macam keperluan dan mesti ada bagl masyarakat Indonesia. Mellhat banyaknya jenls bambu di Indonesla, sangatlah mungkln bahwa bambu telah dimanfaatkan oleh masyarakat Indonesia sejak masa prasejarah (Hidayat, 1991).

Dari hasil pengamatan Jejak daun di situs Wonoboyo dan berdasarkan tinjauan dalam bahasan diatas sebaglan besai ada lenis tumbuhan seperti tercantum dalam relief Karmawibhangga, dan sebagian yang tidak ada. Jenls tumbuhan yang terbatas dapat menunjukkan keberadaan tumbuhan tersebut hidup pada lahan yang bagalmana?, apakah kelompok yang biasa tumbuh atau di tanam di pekarangan, tegalan, sawah, perkebunan, hutan atau lahan lainnya.

Menitikberatkan dari pemanfaatan jenis tumbuhan yang ditemukan pada situs tersebut yaitu Jenis-jenis tumbuhan sebagai sumber pangan seperti: durian, nangka, mangga, jeruk, dan keluwih, dan jenis-jenis tumbuhan sebagai bahan bangunan: jatl, waru dan bambu. Apabila tetumbuhan tersebut dimanfaatkan seperti manfaatnya pada masa sekarang, seperti apa yang telah dlgambarkan pada relief Karmawibhangga diduga tetumbuhan tersebut hidup pada habitat pemukiman atau sudah dibudidayakan oleh manusia. Dengan data jenis tumbuhan diatas dan dibantu dengan temuan lain yang bersifat artefaktual maka dapat membantu dan memperjelas untuk Interpretasi situs ini, sehingga dapat disimpulkan areal situs Wonoboyo lebih cenderung menguatkan ke arah status situs pemukiman (settlement). 


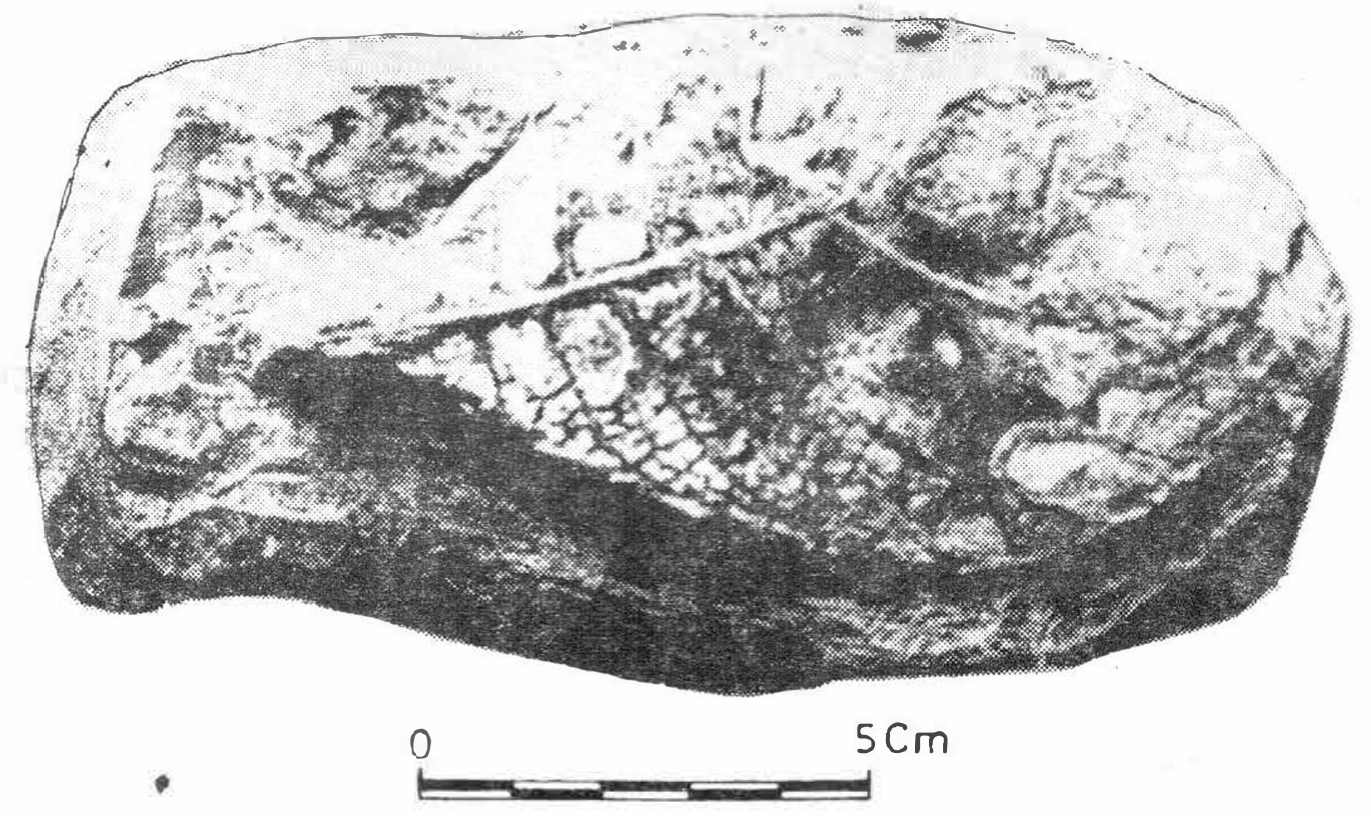

Foto 1. Jejak daun Nangka (Artocarpus heterophyHla Lamk.) pada kotak i' 13

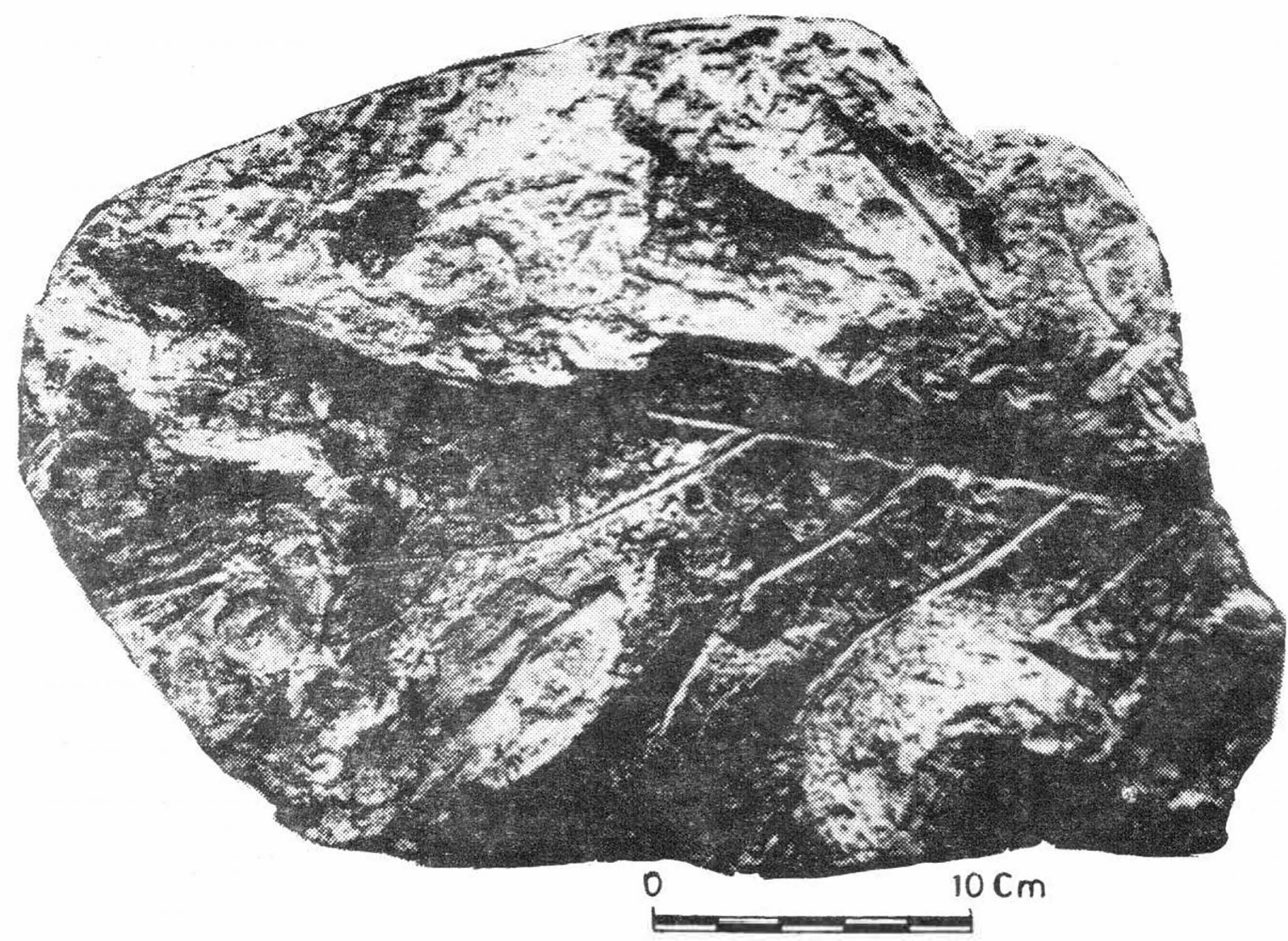

Foto 2. Jejak daun Keluwih (Artocarpus comunis Forst.) pada kotak i" 13 


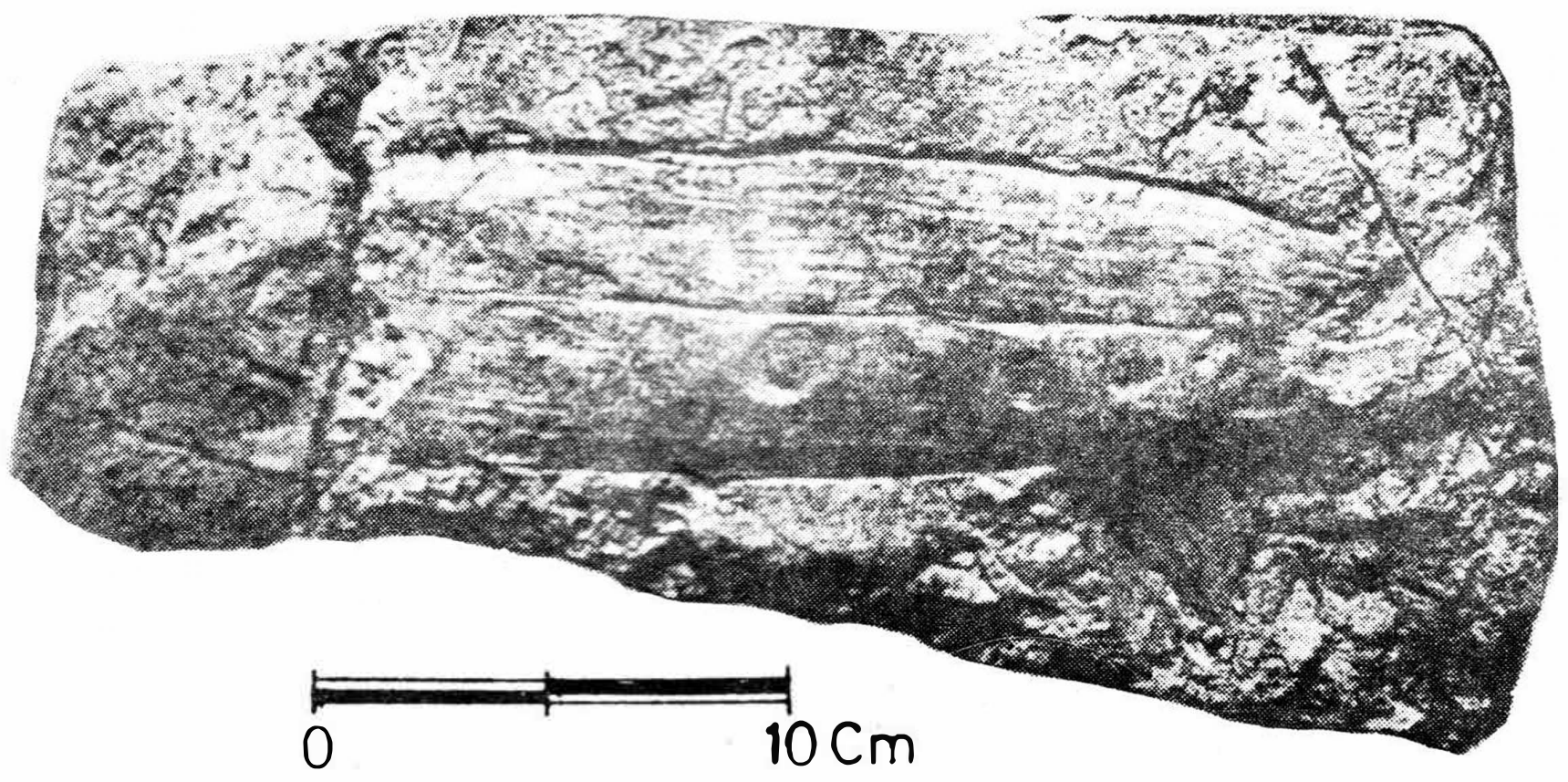

Foto 3. Jejak daun Bambu (Bambusa sp.) pada kotak om 57

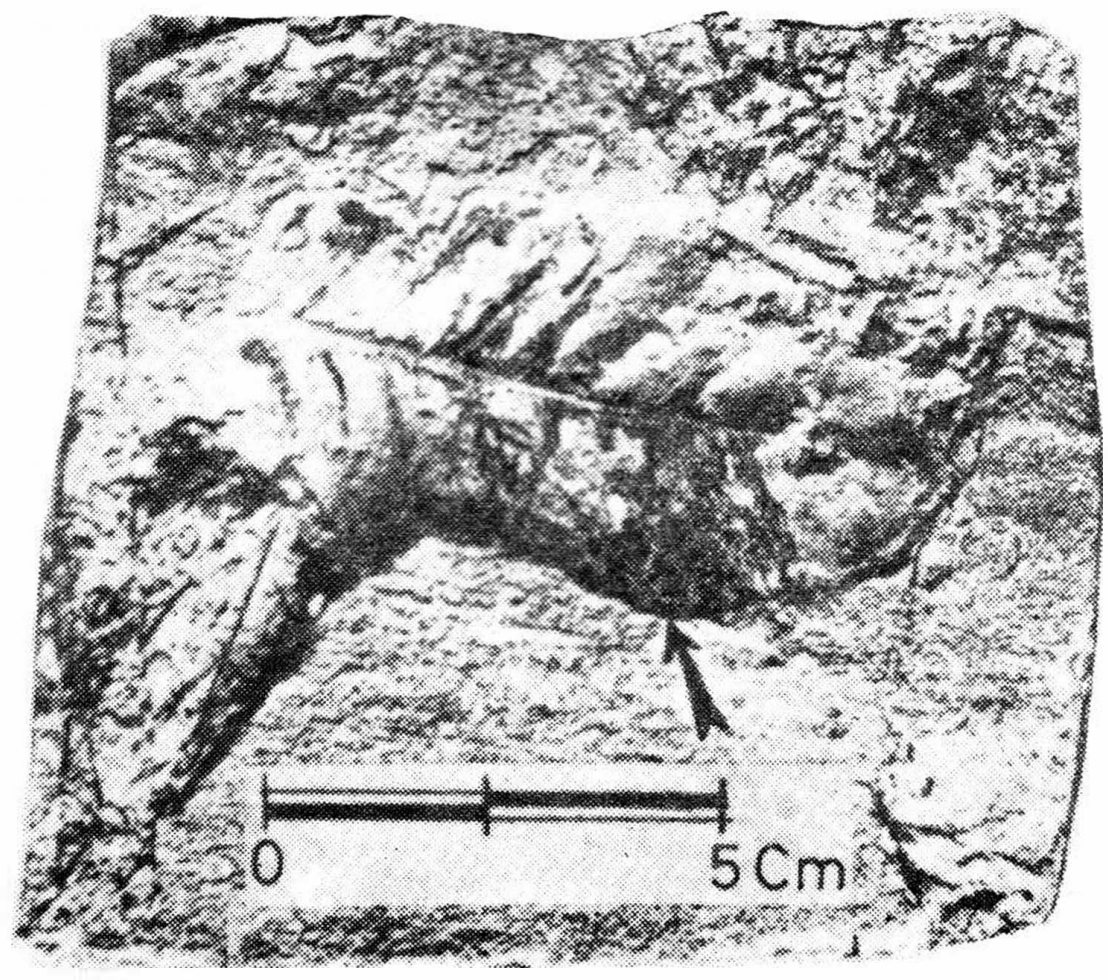

Foto 4. Jejak daun Jeruk (Cytrus maxima) pada kotak $0^{\mathrm{m}} 57$ 


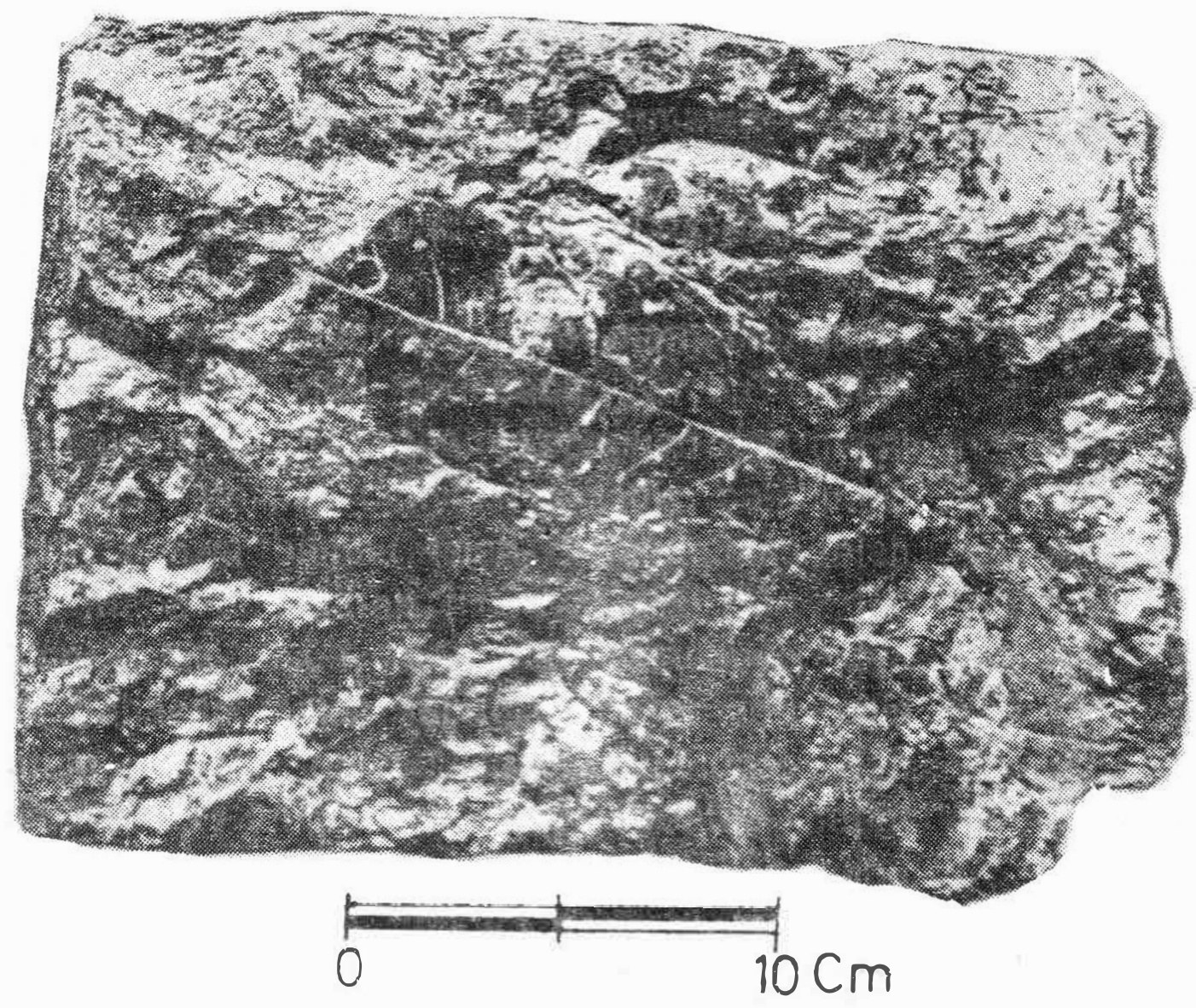

Foto 5. Akumulasi jejak daun pada kotak o" 57 


\section{KEPUSTAKAAN}

Anonim. 1991. Laporan Hasll Penolltlan Arkoologl Sltus Wonoboyo. Tim Penelitlan Arkeologl Situs Wonoboyo. Balal Arkeologi Yogyakarta. (tldak diterbitkan)

1992. Laporan Keglatan Penentuan Batas Wllayah Cagar Budaya Dalam Rangka Penyolamatan Situs Wonoboyo. Bakosurtanal, Ditlinblnjarah dan Fakultas Geografl UGM. (tldak diterbitkan).

Backer, C.A. dan Brink, R.C. Bakhuizen Van Den. 1968. Flora of Java (Spermatophytes Only). Vol. 1 - III. Wolters Noodhoff N.V. Groningen - The Netherlands.

Dimbleby, Geoffrey. 1978. Plants and Archaeology - The Archaeology of The Soll. Paladin Granada Publishing. London - Toronto - Sydney - New York.

Hidsysl, M. (1991). Kemungkinsn Penggunsen Bsmbu Sebsgal Wsdsh Psds Mssysrsksl Ulu Lesng I. Berksls Arkeologl, 12(1), 1ç19. hllps:/l dol.org/10.3088 3/Jbs.v1211.555

Lawrence, George H.M. 1968. Taxonomy of Vascular Plants. The Macmillan Company. New York.

Mattew, H.W. 1964. Fosll and Introduction to Prehlatoric Life. Third Edition. Barness \& Noble. Inc. New York, Publisher.

Steenls, C.G.G.J. van. 1988. Flora. PT. Pradnya Paramlta, Jakarta

Sukardl, Kresno Yullato. 1986. Sumber Daya Pangan Pada Masyarakat Jawa Kuno: Data Arkoologl Sojarah Abad IX - X Masohl. vlde Pertemuan IImlah Arkeologl IV. buku I. Manusla, Ungkungan Hidup dan Toknologl. Proyek Penelltlan Purbakala Jakarta - Departemen Pendldikan dan 
Kebudayaan.

Sulistiarini, Diah. 1991. vide Enslklopedi Masional Indonesla. Jilid 15. PT. Clpta Adi Pustaka. Jakarta. Hal. 328.

Utami, Debora. 1979. Botani. Fakultas Blologi Universltas Jenderal Soedirman, Purwokerto. (tidak diterbltkan)

Widjaja, Elizabeth A. 1989. vide Enslklopedl Naslonal Indonesia. Jilid 3. PT. Cipta Adl Pustaka. Jakarta. Hal 106110. 